\title{
2 Longitudinal Analysis of the Role of Family Functioning 3 in Substance Use $\equiv$
}

4 Inmaculada Sánchez-Queija ${ }^{1}$ (1) Alfredo Oliva ${ }^{1} \cdot$ Águeda Parra $^{1} \cdot$ Carlos Camacho $^{2}$

6 C Springer Science+Business Media New York 2015
7 Abstract Substance use during adolescence and emerg8 ing adulthood is a risk factor for subsequent substance 9 abuse, and it may be related to emotional and behavioral 10 problems. Research shows the importance of family rela11 tionships in preventing substance use. However, much of 12 the research in this field comes from large cross-sectional 13 and epidemiological studies, and there is a lack of longi14 tudinal studies that analyze both the intra-individual 1 mange and the protection factors associated to it. Using 16 HLM analysis, the present longitudinal study found a linear 17 increase of substance use throughout adolescence and 18 emerging adulthood. We found no differences in early 19 adolescence between sexes, but boys increased substance 26 mase more than girls throughout adolescence. Moreover, 21 adolescents who remembered caring mothers during 22 childhood reported less substance use during early ado23 lescence, and those with more cohesive families showed 24 less increase in substance use during adolescence and

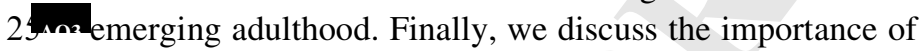
26 family care and family cohesion on preventing substance 28 use during adolescence and emerging adulthood.

29 Keywords Family - Substance use - Adolescence ·

30 Emerging adulthood $\cdot$ Longitudinal analysis

A1 $\square$ Inmaculada Sánchez-Queija

A2 queija@us.es

A3 1 Department of Developmental and Educational Psychology, A4 University of Seville, C/ Camilo José Cela, s/n, A5 41018 Seville, Spain

A6

2 Department of Experimental Psychology, University of Seville, Seville, Spain

\section{Introduction}

The interval between puberty and early adulthood is a 32 developmental stage in which experimentation and risk- 33 taking are relatively frequent and even normative. From 4 puberty many adolescents begin to consume alcohol, to- 35 bacco, or cannabis (Kuntsche and Müller 2012; Ramos 36 et al. 2011). Throughout adolescence substance use 37 gradually increases until reaching its peak during emerging 38 adulthood, at which point it begins to decrease (Chassin 39 et al. 2004; Maggs and Schulenberg 2004). 40

The fact that substance use is widespread among young 41 people should not lead us to ignore its negative conse- 42 quences for health. Ample empirical evidence indicates 43 that substance abuse provokes important short-, medium- 44 and long-term difficulties, both at the physical and the 45 psychological level (Chassin et al. 2009). There are a great 46 deal of studies revealing that consumption of alcohol and 47 other harmful substances during adolescence can alter the $\quad 48$ normal neurological development of the brain when it is in 49 an intense process of maturation (Lydon et al. 2014; 50 Squeglia et al. 2009; Squeglia et al. 2012). This would have 51 an important impact at psychological and behavioral levels, 52 even facilitating the development of addictive behavior. In 53 fact, early initiation in substance use is one of the main 54 predictors of subsequent abusive consumption (Chambers 55 et al. 2003). Several longitudinal studies have found ado-nos 6 lescents whose early substance use initiation is associated 57 with a significant increase in consumption and worse 58 subsequent consequences (Chassin et al. 2002; Abroms 59 et al. 2005; Wilks et al. 2004). The idea that early sub- 60 stance use can lead to subsequent abusive consumption is 61 also consistent with data from animal experimentation 62 showing that adolescents, in contrast to adults, present a 63 different sensitivity to the effects of drugs, which makes 64

\begin{tabular}{|c|c|c|c|}
\hline Journal : Large 10826 & Dispatch & 19-5-2015 & Pages: 9 \\
\hline $\begin{array}{l}\text { Article No. : } \mathbf{2 1 2} \\
\text { MS Code : JCFS-D-14-00413 }\end{array}$ & $\boldsymbol{V}_{\mathrm{CP}}^{\mathrm{LE}}$ & & $\begin{array}{l}\text { TYPESET } \\
\boldsymbol{\nu}_{\text {DISK }}\end{array}$ \\
\hline
\end{tabular}


them more vulnerable to addictions (Higuera-Matas et al. 2008; Spear and Varlinskaya 2005).

The great social concern generated by adolescent substance use is revealed in the large amount of prevalent data from cross-sectional studies. These studies showed an increase in substance use over time throughout adolescence and emerging adulthood and higher substance use among males compared with females (Jiménez-Iglesias et al. 2013; Kuntsche et al. 2004). Nevertheless, these differences between the sexes are narrowing in many Western countries (Keyes et al. 2011; Kuntsche et al. 2011). However, there is a lack of data coming from longitudinal research that analyzes developmental trajectories of substance use throughout adolescence and emerging adulthood, and none in a Spanish context. But only longitudinal studies allow to identify the diversity of trajectories that are masked in the global substance use increase found in cross-sectional studies (Chassin et al. 2002; Flory et al. 2004; Maggs and Schulenberg 2004; Schulenberg and Maggs 2002). Longitudinal studies indicate that there are no differences in substance use between the sexes at the beginning of adolescence, but males increase substance consumption over time more than females. So, during late adolescence and emerging adulthood men present higher levels of substance use than women (Biehl et al. 2007; Duncan et al. 2006).

Moreover, longitudinal studies also permit us to detect factors related both to the initial levels of substance use and its trajectory through time. Family context can be an important protective factor against problem behaviors, such as substance use (Kelly et al. 2011; Stice and Barrera 1995). Parental control or monitoring has clearly shown its influence in the prevention of substance use (DiClemente et al. 2001; Dick et al. 2007; Dishion and Loeber 1985). Moreover, the affective dimension of parent-child relationships has also been shown to be relevant. Specifically, the affective bond with parents, parental responsiveness and support, and family cohesion are variables that have been postulated to be factors that prevent adolescent substance use (Baumrind 1991; Farrell et al. 1995; Kopac et al. 2012). The mechanisms that may explain this relationship are of two types. Firstly, according to the Theory of Social Control (Akers and Sellers 2004; Gottfredson and Hirschi 1990), adolescents usually show a natural tendency toward deviant behaviors that are offset by the prosocial control carried out by the family and other institutions. When adolescents grow up in an environment of affection and closeness to their parents, they are inclined to act in non deviant ways in order to attain their approval. In contrast, if the parent-child relations are marked by detachment, antisocial tendencies will be openly manifested.

Another mechanism that may justify the relationship between family relationships and substance use is of neuronal character. According to this mechanism, a link between the affective bond established in childhood and substance use can be found. The first data in support of this influence comes from animal experimentation, which has revealed the relation of close physical contact between mother and offspring to the production of oxytocin and dopamine. Taking into account that dopamine plays an important role in prefrontal brain development, it has been proposed that strengthening the inputs of dopamine is the mechanism through which affection in parenting style and warm emotional experiences with parents and caregivers will contribute to the maturity of the prefrontal cortex. Some of the functions of the prefrontal cortex are impulse control, decision-making and anticipation of results (Casey et al. 2011; Eisler and Levine 2002; Somerville et al. 2010; Steinberg 2007). Therefore, such prefrontal maturation promoted by parental affection would allow adolescents a better regulation of their behavior, so preventing the onset of addictions (Steinberg 2007). In fact, there is important empirical support for the relation between low self-control and some risk-taking behaviors such as substance use (De Ridder et al. 2012; Ford and Blumenstein 2013). In a similar vein, there is empirical evidence finding that children living in family contexts characterized by lack of affection and who develop insecure attachments are at greater risk of emotional and behavioral problems in adolescence and emerging adulthood (Cicchetti et al. 1995; Kassel et al. 2007).

The main goal of the present study was to analyze the influence of family relationships on the trend of substance use in a sample of Andalusian (South Spain) youths throughout adolescence and emerging adulthood. The longitudinal design allows us to analyze the intra-individual change in substance use throughout this period, our second goal. Although many studies have focused on some concrete substances such as tobacco or alcohol, in this work, we decided to combine the use of different substances into a single variable, enabling us to compute an interval variable that provides clear advantages for statistical analysis (Simons-Morton 2007). The first step was to analyze the substance use trend throughout adolescence and emerging adulthood. Our hypothesis was that, although there is a general trend of continued increasing substance use, there will be differences between participants, both in consumption at the beginning of adolescence and in the magnitude of the increase over time. The second step was to analyze whether initial substance use and the trajectories followed are different as a function of sex and family cohesion. In this regard, we hypothesized that boys will increase substance consumption over time more than females, and that both initial substance use and its increase over time would be lower among subjects who reported better family relationships. 


\section{Method}

\section{Participants}

This work is a longitudinal study of a specific group of adolescents. It all begins with cross-sectional research on a sample made up of 513 adolescents between 12 and 19 years of age, from ten different schools in the city of Seville (southern Spain) and its province. The choice of primary and secondary schools where the adolescents were recruited took into account criteria such as whether they were rural or urban and the socioeconomic level of the families. For further information about the sampling procedure, see (citation omitted for blind review).

Of the initial sample of 513 adolescents, 136 were early adolescents between 12 and 14 years of age who were followed for 10 years, until the participants reached 21 or 23 years of age. Specifically, all participants completed the assessment instruments at four different stages: early adolescence (Wave 1), mid adolescence (Wave 2), late adolescence (Wave 3), and during early adulthood (Wave 4). There were 136 adolescents for W1, 114 for Wave 2, 101 for Wave 3 and 90 for Wave 4. The final sample included 90 adolescents (Table 1). Of the 136 participants for W1, 90 continued until W4, which is more than twothirds of the initial sample. The average ages in early (W1), mid (W2), late (W3) adolescence and early adulthood (W4) were: $\mathrm{W} 1\left(M_{\mathrm{age}}=13.11 ; \mathrm{SD}=.44\right)$; W2 $\left(M_{\mathrm{age}}=15.38\right.$; $\mathrm{SD}=.56) ; \mathrm{W} 3\left(M_{\mathrm{age}}=17.85 ; \mathrm{SD}=.52\right) ; \mathrm{W} 4\left(M_{\mathrm{age}}=\right.$ 21.73; $\mathrm{SD}=.61)$.

At W4, most of the young people lived with their parents ( $77 \%$ of the boys and $96.4 \%$ of the girls). Half of the boys were employed, $43.3 \%$ exclusively, and $16.7 \%$ combined work with studies. The percentage of girls who were studying was greater-50\% were dedicated exclusively to their university or vocational and educational training, and almost $21 \%$ were also working. None of the females, but one of the males in the sample, had children at the time when the data was collected.

The attrition analysis found no significant differences in terms of sex, parental educational level or rural/urban setting, neither in the variables overprotection nor in family cohesion. However, among those who continued, there were somewhat more adolescents who had attended charter schools compared with those who had attended public schools $\left(\chi^{2}=4.11, p=.043\right.$, Cramer's $\left.V=.042\right)$, and more adolescents who recalled higher maternal care $(F(1$, 129) $\left.=6.13, p=.015, \eta^{2}=.045\right)$.

\section{Procedure}

The first data collection (W1) took place during the 19981999 academic year, from September to June. The second (W2) took place from September 2000 to June 2001, the third (W3) from September 2002 to June 2003 and the fourth (W4) between the end of 2007 and the beginning of 2008.

The first step in W1 was to select the schools. Once the Board of Directors agreed to participate, the classrooms where the data would be collected were selected. Once parental permission was obtained, members of the research team applied the questionnaires anonymously and collectively. Even though participation was voluntary and without rewards, at W1 (13 years old) all students at the classroom filled in the questionnaires. To facilitate the subsequent follow-up, each participant was given a numeric identifier.

For W2, data collection was similar, since most of the girls and boys continued to be enrolled at the same school as in W1. In the third and fourth data collection (W3 and W4), once contact had been made with the adolescents, and they had agreed to continue collaborating in the research project, an appointment was made to complete the questionnaire. In W3 and W4 active consent was obtained from the adolescents, and their anonymity was ensured. In W3 and W4 participants completed the questionnaires individually or collectively in the researchers' office.

\section{Measures}

Parental Bonding Instrument

(PBI; Parker et al. 1979), adapted to Spanish by BallúsCreus (1991) and Gómez-Beneyto et al. (1993). The PBI, used only at W1, assesses the adolescent's recall of the attachment bond with his or her mother during childhood. The 25 items' scale is composed of two dimensions: Care subscale (Crombach's alpha $=.89$ ) and Overprotection subscale (Crombach's alpha $=.83$ ). The items were rated on a four-point Likert scale. High scores on the subscales indicate more mothers' care and overprotection.

Table 1 Sample description

\begin{tabular}{|c|c|c|c|c|c|c|}
\hline \multicolumn{2}{|l|}{ Sex } & \multicolumn{3}{|c|}{ Father socioeconomic status } & \multicolumn{2}{|l|}{ Environment } \\
\hline Boys N (\%) & Girls N (\%) & Low N (\%) & Medium N (\%) & High N (\%) & Rural N (\%) & Urban N (\%) \\
\hline 35 (38.9) & $55(61.1)$ & 40 (46.6) & $19(22.1)$ & $27(31.4)$ & $22(24.4)$ & 68 (75.6) \\
\hline
\end{tabular}

$\begin{array}{lcc}\text { Journal : Large 10826 } & \text { Dispatch : 19-5-2015 } & \text { Pages : 9 } \\ \text { Article No. : } 212 & \text { LE } & \text { TYPESET } \\ \text { MS Code : JCFS-D-14-00413 } & \boldsymbol{V}_{\mathrm{CP}} & \boldsymbol{V}_{\text {DISK }}\end{array}$




\section{Family Cohesion}

We used the Cohesion sub-scale of the Spanish version of the Family Adaptability and Cohesion Scale, (FACES II, Olson et al. 1985). This is a 16 items' likert scale ranging from 1 to 5 that analyses family cohesion. The Spanish version of FACES II and III has been validated and widely used with Spanish and South American samples (López 2002; Martínez-Pampliega et al. 2006). The alpha reliability coefficients were $\mathrm{W} 1 / \mathrm{W} 2 / \mathrm{W} 3 / \mathrm{W} 4=.69 / .84 / .87 / .89$.

\section{Drug Use}

This scale was elaborated for this research and includes four questions referring to consumption of tobacco, cannabis, and alcohol, and episodes of binge drinking (citation omitted for blind review). Tobacco, alcohol and cannabis are the most commonly used substances among Spanish adolescents(Moreno et al. 2013). The adolescents should indicate the level of substance use on a scale ranging between 1 (Never) and 4 (More than five times in your life) in the case of consumption of cannabis and episodes of binge drinking, and between 1 (Never) and 5 (Daily) for alcohol or tobacco consumption (More than 3 daily cigarettes). We decided to ask for information about binge drinking and alcohol consumption in order to differentiate subjects with moderate alcohol consumption from those with a more problematic one. We combined the four ordinal items into a continuous single-interval measure (Simons-Morton 2007). The reliability according to Cronbach's alphas at W1/W2/W3/W4 was .71/.78/.79/.72 respectively.

\section{Data Analysis}

To study the intraindividual change of substance use over time and the influence of the family context in such change, we performed a linear hierarchical model with the statistical package HLM (Raudenbush et al. 2011). This analysis reveals individual patterns of change over time and, at the same time, allows analyzing which variables affect such patterns. That is, it shows the change of the dependent variable (DV) in each individual (Snijder and Bosker 2000). To perform this analysis, firstly, we elaborated the null model to verify possible variability in substance use between subjects throughout time. Subsequently, we performed the model of random intersections to check possible differences at the beginning of the study; and to determine whether the substance use trajectories were different for the participants of the sample. Lastly, we introduced in the model variables that explain both differences between individuals at the beginning of the study, at age 13, and the diverse trajectories they followed throughout adolescence and emerging adulthood. To assess the fit of each model we used two indexes. On the one hand, the deviance provided by the program itself, although there is no required value in order to consider the model correct, better models obtain low deviance indexes (Raudenbush and Bryk 2002). On the other hand, the pseudo $R^{2}$, an index that should be interpreted like the $R^{2}$ of multiple regression. Pseudo $R^{2}$ is obtained by squaring the correlation between the value predicted in the DV by the model and the real value of that DV (Hox 2002; Singer and Willett 2003).

\section{Results}

The results (Table 2) revealed both an increase in substance use during adolescence and emerging adulthood and also an increase in inter-individual variability in substance use over time. There was not a clear developmental trend with regards to family cohesion during the time of the study.

We began the Linear Hierarchical Model (Table 3) by 19 establishing the null model, which showed that the mean 320 consumption at the four measurement times differed be- 321 tween participants, $\delta^{2}=.33, \chi^{2}(89)=277.82, p<.001$. AQ7 22 This value, along with the residual variance, $\delta^{2}=.62$, al- 323 lowed calculation of the intraclass correlation:

$\rho=\frac{\sigma_{r_{0}}^{2}}{\sigma_{r_{0}}^{2}+\sigma_{e}^{2}}=\frac{0.33}{0.33+0.62}=0.35$

Basically, $35 \%$ of the variability in substance consumption throughout adolescence was explained by the subjects. The model showed a deviance of 952.70. The AQ8 28 model of random intersections and slopes (Model 1) 329 showed the variability in consumption among the par- 330 ticipants at the beginning of the investigation, $\sigma_{r_{0}}^{2}=.25, \quad 331$ $p<.001$, and their different evolution across the years of 332 study, $\sigma_{r_{1}}^{2}=.06, p<.001$. This data evidences the fact that 333 there are different individual trajectories. In this model, the 334 deviance dropped to 799.40 .

The next step was to introduce the variable sex at the second level of analysis, both in the intercept and in the slope (Model 2). The results revealed no significant differences in substance use between boys and girls at age 13 . However they presented different slopes throughout adolescence and emerging adulthood: the increase in substance use was lower in girls than in boys. The deviance dropped to 764 .

Model 3 describes the role of care in adolescent substance use, and Model 4 adds overprotection to care. Care and overprotection were included at intercept and at slope. In these two models sex was removed from the intercept because model 2 showed that there were no significant differences between boys and girls at the beginning of the

\section{.} .

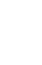
4 
Table 2 Descriptive analysis of the sample as a function of the instruments used

\begin{tabular}{|c|c|c|c|c|c|c|c|c|c|c|c|c|}
\hline & \multicolumn{3}{|c|}{ Wave 1} & \multicolumn{3}{|c|}{ Wave 2} & \multicolumn{3}{|c|}{ Wave 3} & \multicolumn{3}{|c|}{ Wave 4} \\
\hline & $M$ & SD & Range & $M$ & SD & Range & $M$ & SD & Range & $M$ & SD & Range \\
\hline Care & 29.68 & 4.9 & $12-36$ & NA & NA & & NA & NA & & NA & NA & \\
\hline Overprotection & 16.78 & 4.74 & $6-32$ & NA & NA & & NA & NA & & NA & NA & \\
\hline Cohesion & 52.37 & 6.39 & $38-68$ & 56.76 & 9.87 & $24-77$ & 55.6 & 10.46 & $29-79$ & 57.89 & 10.15 & $27-79$ \\
\hline Drug use & 1.43 & .55 & $1-3.75$ & 2.04 & .88 & $1-4.25$ & 2.45 & .95 & $1-4.25$ & 2.65 & .96 & $1-4.67$ \\
\hline
\end{tabular}

$N A$ not applicable

study. The sex variable is kept at level 2 (slope). As can be seen in Models 3 and 4, family history influenced the onset level of substance use at age 13 (intercept), but not the increase produced throughout adolescence and emerging adulthood (slope). The data indicated that at age 13, adolescents who recalled having received more care in childhood showed lower substance use. Overprotection did not significantly contribute to change in substance use.

Model 5 shows the role of family cohesion, both at the intercept and in the interaction with the slope, keeping the sex variable at level 2 . The data indicates that adolescents who reported lower family cohesion showed more substance use at age 13, and also increased their consumption over time.

Lastly, Model 6 introduces the variables maternal care at the intercept (level 1), and sex and family cohesion at slope (level 2). This model shows that adolescents who recalled more maternal care during childhood consumed less substance. Moreover, boys increased substance consumption more than girls and children in families with lower cohesion showed greater increase in substance use over time. This model explained $32 \%$ of the variability in substance use. In turn, the respective PseudoR ${ }^{2}$ s have shown the improvement of the diverse models both at the beginning of the research (intercept) and during adolescent and emerging adulthood (slopes). The best model was number 6.

\section{Discussion}

The results of the present study showed different trajectories of substance use during adolescence and emerging adulthood, and also showed that family relationships influence both the initial level of substance use at age 13 and the different trajectories of substance use throughout time.

Adolescents presented different levels of substance use at age 13 and they also experienced different increasing substance use trajectories during the next 10 years. Previous studies of substance use throughout adolescence and emerging adulthood usually describe the increase of consumption and its normative trajectory, without analyzing individual differences. Few works have taken into account the advantages of hierarchical methods, which provide a more complete picture of individual change, showing the quantity and structure of intraindividual change (Ram and Gerstorf 2009). Our study extends prior works on substance use by focusing not so much on normative changes, as on the within-subject variability hidden behind the linear trajectory of increased consumption between initial adolescence and emerging adulthood. In addition, our data has also allowed us to determine the relationship between some variables and the magnitude of this increase. Firstly, significant sex differences emerged. Although in early adolescence boys and girls substance use was similar, boys increased their consumption throughout time more than girls.

Boys' higher substance use, especially at late adolescence, has been found in diverse studies, both in Spain (ESTUDES 2013; Ramos and Moreno 2010) and in other western countries (Kuntsche and Müller 2012; Kuntsch et al. 2004). There is evidence indicating that in recent decades the gap between boys and girls has shrunk as a consequence of changing lifestyles (Keyes et al. 2011; Kuntsche et al. 2011), such that some studies find no sex differences in adolescence (Moreno et al. 2013). However, in late adolescence and early adulthood, substance use is usually more frequent in males (Evans and Jacobson 2012; Wilsnack et al. 2002). An explanation for this higher consumption among boys is that girls present earlier psychosocial maturity, which could lead them to stabilizing substance use sooner. Some studies have also outlined the role of greater parental monitoring of girls in their lower substance use (Svensson 2003). Whereas in the case of boys such monitoring is probably lower from late adolescence onwards, in the case of girls, it persists for more years.

The results also confirm the hypothesis proposed about the role of family relationships, both in substance use at the beginning of adolescence and in its change throughout time. We found that maternal care during childhood was significantly related to consumption at age 13 in that substance use was lower among those adolescents who recalled more caring relationships. This memory had no relationship with the trajectory of substance use from that age onwards. 


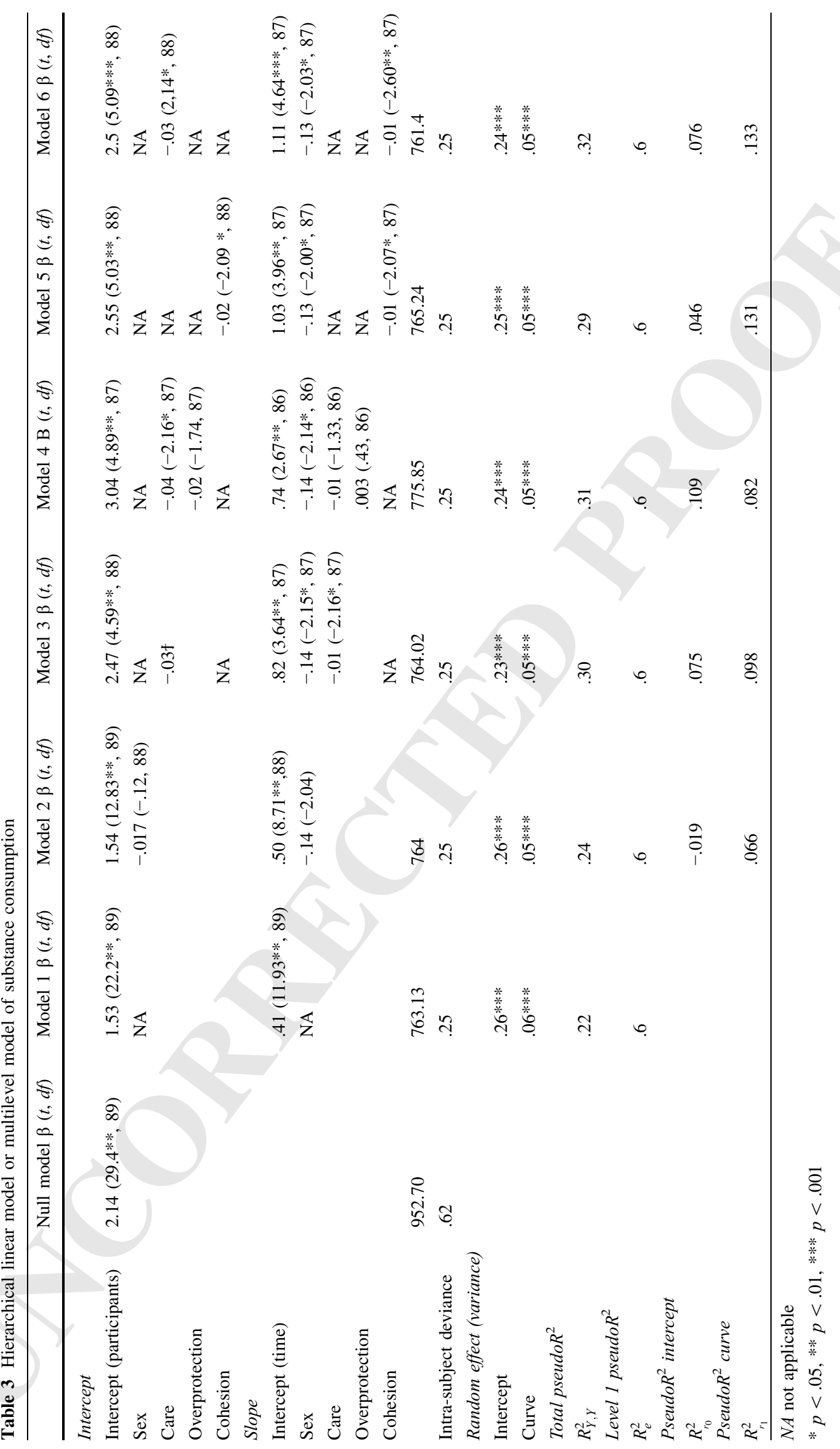

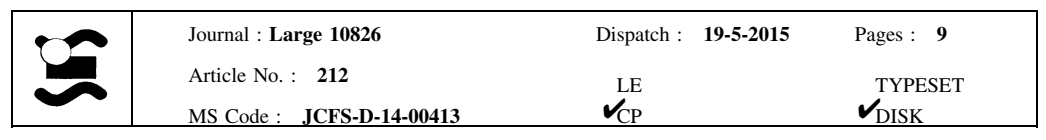


As commented in the introduction, there are at least two possible explanations for the relationship between care and low substance use at age 13. On the one hand, according to the social control theory (Akers and Sellers 2004), the bond with the parents would help the adolescent to accept conventional values and avoid engaging in misbehavior as a way of achieving parental approval. On the other hand, we can also refer to the probable positive effect that care during childhood could have on the development of the prefrontal cortex. This development would promote emotional and behavioral regulation, preventing subsequent substance use (Steinberg 2007).

There is also data indicating that insecure attachment, probably established due to a lack of parents' support and affection, is associated with abusive substance use (Brennan and Shaver 1995; Caspers et al. 2005; Kassel et al. 2007). There is even more abundant evidence supporting the relationship between insecure attachment and diverse indicators of psychological distress, such as low self-esteem (Griffin and Bartholomew 1994; Gamble and Roberts 2005), anxiety (Warren et al. 1997) or difficulties in emotional regulation (Thorberg and Lyvers 2010). These emotional difficulties play an essential role in the etiology of substance abuse, as they may represent an avoidant coping strategy to relieve the psychological distress generated by stressful situations (Kassel et al. 2007; McNally et al. 2003).

The fact that low cohesion in the family context was associated with an increase in substance use during adolescence and emerging adulthood supports this idea. The individuals who had worse family relationships were less likely to approach family figures as a way of coping with adversity. Instead, they tend to seek out other less healthy strategies, such as substance use, to regulate their negative moods and reduce anxiety (Thorberg and Lyvers 2010). It must be taken into account that, during adolescence and emerging adulthood, youths must face many challenges or developmental tasks that will test their coping strategies and may generate them a lot of stress (Arnett 2005).

The results of our study revealed that, although consumption of substances such as tobacco, alcohol, or cannabis are common during adolescence and emerging adulthood, caring family relationships play a significant role in its prevention. Thus, boys and girls who have experienced care and support during childhood, and enjoy a more cohesive family environment during adolescence and emerging adulthood, showed less substance use. Although they initiate consumption during these years, it does not reach the level of substance use observed among those who have grown up in less favorable family contexts.

\section{Limitations, Future Directions and Implications}

To conclude, we must refer to some limitations of the study, such as having a sample of only 90 subjects, which has placed some limits on the generalization of the results obtained. Also, having used self-reports as the only source of information may have increased the relationships found between the variables of the study. Lastly, the longitudinal nature of the study imposes an important limitation related to the use of the instruments, because the selection of measures at the beginning of the study clearly conditions the instruments employed in subsequent data collections. In spite of these limitations, the extension of the study throughout adolescence and emerging adulthood makes it a rare work in Spain. Likewise, the statistical techniques employed have allowed us to take a more in depth look at results found in previous research and to find responses that are not easily accessible from more traditional statistics.

Future studies should delve into the role of affection in the process underlying the relationship between the family context and substance use, as well as in the manner of alleviating the negative consequences of this consumption. In any case, public policies destined towards programs that help promote positive parenting seem necessary, to enhance parenting skills related to supporting children, showing affection and increasing family cohesion. These policies will be profitable both on a human level, by improving the capacity of boys and girls to regulate their own behavior in avoiding not only the abusive use of substances but also other externalizing problems, and on an economic level, by reducing the utilization of public health services.

\section{References}

Akers, R. L., \& Sellers, C. (2004). Criminological theories:AQ9 11 Introduction, evaluation, and application ( ${ }^{\mathrm{a}}$ ed.). Los Angeles: Roxbury Publishing.

Arnett, J. J. (2005). The developmental context of substance use in emerging adulthood. Journal of Drug Issues, 35, 235-254. doi:10.1177/002204260503500202.

Ballús-Creus, C. (1991). Adaptación del Parental Bonding Instrument [Parental Bonding Instrument adaptation]. Barcelona: Escola Profesional de Psicología Clínica.

Baumrind, D. (1991). The influence of parenting style on adolescent competence and substance use. The Journal of Early Adolescence, 11, 56-95. doi:10.1177/0272431691111004.

Biehl, M. C., Natsuaki, M. N., \& Ge, X. (2007). The influence of puberal timing on alcohol use and heavy drinking trajectories. Journal of Youth and Adolescence, 36, 153-167.

Brennan, K. A., \& Shaver, P. R. (1995). Dimensions of adult attachment, affect regulation, and romantic relationship functioning. Personality and Social Psychology Bulletin, 21, 267283. doi: $10.1177 / 0146167295213008$.

Casey, B. J., Jones, R. M., \& Somerville, L. H. (2011). Braking and accelerating of the adolescent brain. Journal of Research on Adolescence, 21, 21-33. doi:10.1111/j.1532-7795.2010.00712.x.

Caspers, K. M., Cadoret, R. J., Langbehn, D., Yucuis, R., \& Troutman, B. (2005). Contributions of attachment style and perceived social support to lifetime use of illicit substances. Addictive Behaviors, 30, 1007-1011. doi:10.1016/j.addbeh.2004.09.001. 
Chambers, R. A., Taylor, J. R., \& Potenza, M. N. (2003). Developmental neurocircuitry of motivation in adolescence: A critical period of addiction vulnerability. American Journal of Psychiatry, 160, 1041-1052. doi:10.1176/appi.ajp.160.6.1041.

Chassin, L., Hussong, A. M., Barrera, M., Molina, B. S. G., Trim, R., \& Ritter, J. (2004). Adolescent substance use. In R. M. Lerner \& L. Steinberg (Eds.), Handbook of adolescent psychology (2a ed., pp. 665-696). Hoboken, NJ: Wiley.

Chassin, L., Hussong, A., \& Beltran, I. (2009). Adolescent substance use. In R. Lerner \& L. Steinberg (Eds.), Handbook of adolescent psychology (3rd ed., pp. 723-765). Hoboken, NJ: Wiley.

Chassin, L., Pitts, S. C., \& Prost, J. (2002). Binge drinking trajectories from adolescence to emerging adulthood in a high-risk sample: Predictors and substance abuse outcomes. Journal of Consulting and Clinical Psychology, 70, 67-78. doi:10.1037/0022-006X.70. 1.67.

Chen, P., \& Jacobson, K. C. (2012). Developmental trajectories of substance use from early adolescence to young adulthood: Gender and racial/ethnic differences. Journal of Adolescent Health, 50, 154-163. doi:10.1016/j.jadohealth.2011.05.013.

Cicchetti, D., Toth, S. L., \& Lynch, M. (1995). Bowlby's dream comes full circle: The application of attachment theory to risk and psychopathology. Advances in Clinical Child Psychology, 17, 1-75.

De Ridder, D., Lensvelt-Mulders, G., Finkenauer, C., Stok, F. M., \& Baumeister, R. F. (2012). Taking stock of self-control. A metaanalysis of how trait self-control relates to a wide range of behaviors. Personality and Social Psychology Review, 16, 76-99. doi: $10.1177 / 1088868311418749$.

Dick, D. M., Viken, R., Purcell, S., Kaprio, J., Pulkkinen, L., \& Rose, R. J. (2007). Parental monitoring moderates the importance of genetic and environmental influences on adolescent smoking. Journal of Abnormal Psychology, 116, 213-218. doi:10.1037/ 0021-843X.116.1.213

DiClemente, R. J., Wingood, G. M., Crosby, R., Sionean, C., Cobb, B. K., Harrington, K., \& Kim, M. (2001). Parental monitoring: Association with adolescents' risk behaviors. Pediatrics, 107, 1363-1368. doi:10.1542/peds.107.6.1363.

Dishion, T. J., \& Loeber, R. (1985). Male adolescent marijuana and alcohol use: The role of parents and peers revisited. American Journal of Drug Alcohol Abuse, 11, 11-25. doi:10.3109/ 00952998509016846.

Duncan, S. C., Duncan, T. E., \& Strycker, L. A. (2006). Alcohol use from ages 9-16: A cohort-sequential latent growth model. Drug and Alcohol Dependece, 81, 71-81. doi:10.1016/j.drugalcdep. 2005.06.001.

Eisler, R., \& Levine, D. S. (2002). Nurture, nature, and caring: We are not prisoners of our genes. Brain and Mind, 3, 9-52.

ESTUDES. Encuesta estatal sobre uso de drogas en enseñanzas secundarias. 2012/13, España. (National Survey on Drug Use at Secondary Schools, 2013/2013) Ministerio de Sanidad, Servicios Sociales e Igualdad, Secretaría de Estado de Servicios Sociales e Igualdad, Delegación del Gobierno para el Plan Nacional sobre Drogas; [consultado el 01/07/2014]. Retrieved for: http://www. pnsd.msc.es/Categoria2/observa/pdf/PresentESTUDES2012 2013.pdf.

Farrell, M. P., Barnes, G., \& Banerjee, S. (1995). Family cohesion as a buffer against the effects of problem-drinking fathers on psychological distress, deviant behavior, and heavy drinking in adolescents. Journal of Health and Social Behavior, 36(4), 337-385.

Flory, K., Lynam, D., Milich, R., Leukefeld, C., \& Clayton, R. (2004). Early adolescent through young adult alcohol and marijuana use trajectories: Early predictors, young adult outcomes, and predictive utility. Development and Psychopathology, 16, 193-213. doi:10.1017/S0954579404044475.
Ford, J. A., \& Blumenstein, L. (2013). Self-control and substance use among college students. Journal of Drug Issues, 43, 56-68. doi:10.1177/0022042612462216.

Gamble, S. A., \& Roberts, J. E. (2005). Adolescents' perceptions of primary caregivers and cognitive style: The roles of attachment security and gender. Cognitive Therapy and Research, 29, 123141. doi:10.1007/s10608-005-3160-7.

Gómez-Beneyto, M., Pedrós, A., Tomás, K., \& Leal, C. (1993). Psychometric properties of the parental bonding instrument in a spanish sample. Social Psychiatry and Psychiatric Epidemiology, 28, 252-255. doi:10.1007/BF00788745.

Gottfredson, M., \& Hirschi, T. (1990). A general theory of crime. Stanford: Stanford University Press.

Griffin, D. W., \& Bartholomew, K. (1994). Models of the self and other: Fundamental dimensions underlying measures of adult attachment. Journal of Personality and Social Psychology, 67, 430-445. doi:10.1037/0022-3514.67.3.430.

Higuera-Matas, A., Soto-Montenegro, M. L., del Olmo, N., Miguèns, M., Torres, I., Vaquero, J. J., \& Ambrosio, E. (2008). Augmented acquisition of cocaine self-administration and altered brain glucose metabolism in adult female but not male rats exposed to a cannabinoid agonist during adolescence. Neuropsychopharmacology, 33, 806-813. doi:10.1038/sj.npp. 1301467.

Hox, J. J. (2002). Multilevel analysis. Techniques and applications. London: Lawrence Erlbaum Associates.

Jiménez-Iglesias, A., Moreno, M. C., Rivera, F., \& García-Moya, I. (2013). The role of the family in promoting responsible substance use in adolescence. Journal of Child and Family Studies, 22, 585-602. doi:10.1007/s10826-013-9737-y.

Kassel, J. D., Wardle, M., \& Roberts, J. E. (2007). Adult attachment security and colleage student substance abuse. Addictive Behaviors, 32, 1164-1176. doi:10.1016/j.addbeh.2006.08.005.

Kelly, A. B., O'Flaherty, M., Toumbourou, J. W., Connor, J. P., Hemphill, S. A., \& Catalano, R. F. (2011). Gender differences in the impact of families on alcohol use: A lagged longitudinal study of early adolescents. Addiction, 106, 1427-1436. doi:10. 1111/j.1360-0443.2011.03435.x.

Keyes, K. M., Li, G., \& Hasin, D. S. (2011). Birth cohort effects and gender differences in alcohol epidemiology: A review and synthesis. Alcoholism, Clinical and Experimental Research, 35, 2101-2112. doi:10.1111/j.1530-0277.2011.01562.x.

Kopak, A. M., Chia-Chen, A., Haas, S., \& Gillmore, M. R. (2012). The importance of family factors to protect against substance use related problems among Mexican heritage and White youth. Drug and Alcohol Dependence, 124, 34-41. doi:10.1016/j. drugalcdep.2011.12.004.

Kuntsche, E., Kuntsche, S., Knibbe, R., Simons-Morton, B., Farhat, T., Hublet, A., et al. (2011). Cultural and gender convergence in adolescent drunknness. Evidence from 23 European and North American countries. Archives of Pediatrics and Adolescent Medicine, 165, 152-158. doi:10.1001/archpediatrics.2010.191.

Kuntsche, E., \& Müller, S. (2012). Why do young people start drinking? Motives for first-time alcohol consumption and links to risky drinking in early adolescence. European Addiction Research, 18, 34-39. doi:10.1159/000333036.

Kuntsche, E., Rehm, J., \& Gmel, G. (2004). Characteristics of binge drinkers in Europe. Social Science and Medicine, 59, 113-127. doi:10.1016/j.socscimed.2003.10.009.

López, S. (2002). The FACES II in the evaluation of family cohesion and adaptability. Psicothema, 14, 159-166.

Lydon, D. M., Wilson, S. J., Child, A., \& Geier, C. F. (2014). Adolescent brain maturation and smoking: What we know and where we're headed. Neuroscience and Biobehavioral Reviews, 45, 323-342. doi:10.1016/j.neubiorev.2014.07.003.

\begin{tabular}{|c|c|c|c|c|}
\hline & Journal : Large 10826 & Dispatch : & 19-5-2015 & Pages: 9 \\
\hline & $\begin{array}{l}\text { Article No. : } 212 \\
\text { MS Code : JCFS-D-14-00413 }\end{array}$ & $\begin{array}{l}\mathrm{LE} \\
\boldsymbol{\gamma}_{\mathrm{CP}}\end{array}$ & & $\begin{array}{l}\boldsymbol{V}_{\text {DISK }}^{\text {TYPESET }} \\
\end{array}$ \\
\hline
\end{tabular}


Maggs, J. L., \& Schulenberg, J. E. (2004). Trajectories of alcohol use during the transition to adulthood. Alcohol Research and Health, 28, 195-201.

Martínez-Pampliega, A., Iraurgi, I., Galíndez, E., \& Sanz, M. (2006). Family adaptability and cohesion evaluation scale (FACES): Development of a 20 items version in Spanish. International Journal of Clinical and Health Psychology, 6, 317-338.

McNally, A. M., Palfai, T. P., Levine, R. V., \& Moore, B. M. (2003). Attachment dimensions and drinking-related problems among young adults the meditational role of coping motives. Addictive Behaviors, 28, 1115-1127. doi:10.1016/S0306-4603(02)00224-1.

Moreno, C., Ramos, P., Rivera, F., Sánchez-Queija, I., JiménezIglesias, A., García-Moya, I., Funch, N. (2013). Los estilos de vida y la salud de los adolescentes españoles a lo largo de la primera década del milenio. El estudio Health Behaviour in School-aged Children (HBSC) 2002-2006-2010. [Spanish Adolescent's Lifestyle and Health across first decade of millennium. Health Behaviour in School-aged Children (HBSC) Study 20022006-2010]. Madrid: Ministerio de Sanidad, Servicios Sociales e Igualdad. NIPO: 680-13-047-X.

Olson, D. H., Portner, J., \& Lavee, Y. (1985). Family adaptability and cohesion scale. Minneapolis: University of Minnesota.

Parker, G., Tupling, H., \& Brown, B. (1979). A parental bonding instrument. British Journal of Medical Psychology, 52, 1-10. doi:10.1111/j.2044-8341.1979.tb02487.x.

Ram, N., \& Gerstorf, D. (2009). Methods for the study of development-Developing methods. Research in Human Development, 6, 61-73. doi:10.1080/15427600902911114.

Ramos, P., \& Moreno, C. (2010). Situación actual del consume de sustancias en los adolescentes españoles: Tabaco, alcohol, cannabis y otras drogas ilegales [Current situation of sustance use among spanish adolescents: Tobacco, alcohol, cannabis and others illegal drugs]. Health and Addictions, 10, 13-36.

Ramos, P., Moreno, M. C., Rivera, F., \& López, A. (2011). The classification of Spanish adolescents based on substance consumption patterns and the analysis of the relationships within their social developmental contexts. The Spanish Journal of Psychology, 14, 734-745. doi:10.5209/rev_SJOP.2011.v14.n2.21.

Raudenbush, S. W., \& Bryk, A. S. (2002). Hierarchical linear models. Aplications and data analysis methods. London: Sage.

Raudenbush, S. W., Bryk, A. S., \& Congdon, R. (2011). HLM 7 for windows [computer software]. Skokie, IL: Scientific Software International Inc.

Schulenberg, J. E., \& Maggs, J. L. (2002). A developmental perspective on alcohol use and heavy drinking during adolescence and the transition to young adulthood. Journal of Studies on Alcohol and Drugs, supplement, 14, 54-70.
Simons-Morton, B. G. (2007). Social influences on adolescent substance use. American Journal of Health Behavior, 6, 672-684.

Singer, J. D., \& Willett, J. B. (2003). Applied longitudinal data analysis: Modeling change and event occurrence. New York: Oxford Univ Press.

Snijder, T. A., \& Bosker, R. J. (2000). Multilevel analysis. An introduction to basic and advanced multilevel modeling. London: Sage.

Somerville, L. H., Jones, R. M., \& Casey, B. J. (2010). A time of change: Behavioral and neural correlates of adolescent sensitivity to appetitive and aversive environmental cues. Brain and Cognition, 72, 124-133. doi:10.1016/j.bandc.2009.07.003.

Spear, L. P., \& Varlinskaya, E. I. (2005). Adolescence. Alcohol sensitivity, tolerance, and intake. Recent Developments in Alcoholism, 17, 143-159.

Squeglia, L. M., Jacobus, J., \& Tapert, S. F. (2009). The influence of substance use on adolescent brain development. Clinical EEG and Neuroscience, 40, 31-38. doi:10.1177/155005940904000110.

Squeglia, L. M., Pulido, C., Wetherill, R. R., Jacobus, J., Brown, G. G., \& Tapert, S. (2012). Brain response to working memory over three years of adolescence: Influence of initiating heavy drinking. Journal of Studies on Alcohol and Drug, 73, 749-760.

Steinberg, L. (2007). Risk taking in adolescence. New perspectives from brain and behavioral science. Current Directions in Psychological Science, 16, 55-59. doi:10.1111/j.1467-8721.2007.00475.x.

Stice, E., \& Barrera, M. (1995). A longitudinal examination of the reciprocal relations between perceived parenting and adolescents' substance use and externalizing behaviors. Developmental Psychology, 31, 322-334. doi:10.1037/0012-1649.31.2.322.

Svensson, R. (2003). Gender differences in adolescent drug use. The impact of parental monitoring and peer deviance. Youth and Society, 34, 300-329. doi:10.1177/0044118X02250095.

Thorberg, F. A., \& Lyvers, M. (2010). Attachment in relation to affect regulation and interpersonal functioning among substance use disorder in patients. Addiction Research \& Theory, 18, 464-478. doi:10.3109/16066350903254783.

Warren, S. L., Huston, L., Egeland, B., \& Sroufe, L. A. (1997). Child and adolescent anxiety disorders and early attachment. Journal of the American Academy of Child and Adolescent Psychiatry, 36, 637-644. doi:10.1097/00004583-199705000-00014.

Wilks, T. A., Resko, J. A., Ainette, M. G., \& Mendoza, D. (2004). Smoking onset in adolescence: A person-centered analysis with time-varying predictors. Health Psychology, 32, 158-167. doi:10.1037/0278-6133.23.2.158.

Wilsnack, R., Vogeltanz, N. D., Wilsnack, S., \& Harris, T. R. (2002). Gender differences in alcohol consumption and adverse drinking consequences: Cross-cultural patterns. Addiction, 9, 251-265. doi:10.1046/j.1360-0443.2000.95225112.x.

\begin{tabular}{|c|c|c|}
\hline Journal : Large 10826 & Dispatch : $19-5-2015$ & Pages: 9 \\
\hline $\begin{array}{l}\text { Article No. : } 212 \\
\text { MS Code : JCFS-D-14-00413 }\end{array}$ & $\begin{array}{l}\mathrm{LE} \\
\boldsymbol{\nu}_{\mathrm{CP}}\end{array}$ & $\begin{array}{l}\text { TYPESET } \\
\boldsymbol{\gamma}_{\text {DISK }}\end{array}$ \\
\hline
\end{tabular}


Journal : 10826

Article : 212

\section{Author Query Form}

䈝 Springer

the language of science

\section{Please ensure you fill out your response to the queries raised below and return this form along with your corrections}

\section{Dear Author}

During the process of typesetting your article, the following queries have arisen. Please check your typeset proof carefully against the queries listed below and mark the necessary changes either directly on the proof/online grid or in the 'Author's response' area provided below

\begin{tabular}{|c|c|c|}
\hline Query & Details Required & Author's Response \\
\hline AQ1 & $\begin{array}{l}\text { Please check and confirm the author names and initials are correct. Also, kindly confirm the details in the } \\
\text { metadata are correct. }\end{array}$ & \\
\hline AQ2 & $\begin{array}{l}\text { Please check and confirm that the authors and their respective affiliations have been correctly identified } \\
\text { and amend if necessary. }\end{array}$ & \\
\hline AQ3 & Please confirm the inserted city name is correct and amend if necessary. & \\
\hline AQ4 & Please confirm the section headings are correctly identified. & \\
\hline AQ5 & $\begin{array}{l}\text { References Abroms et al. (2005), Evans and Jacobson (2012) are cited in text but not provided in the } \\
\text { reference list. Please provide references in the list or delete these citations. }\end{array}$ & \\
\hline AQ6 & Please check the layout of Table 3 and correct if necessary. & \\
\hline AQ7 & Please check and confirm the term $\mathrm{R}_{\mathrm{yy}}^{2}$ in Table 3. & \\
\hline AQ8 & Please provide a definition for the significance of dagger in the Table 3. & \\
\hline AQ9 & Please check and confirm the edition number for the reference Akers and Sellers (2004). & \\
\hline AQ10 & $\begin{array}{l}\text { Reference Chen and Jacobson (2012) are given in list but not cited in text. Please cite in text or delete } \\
\text { from list. }\end{array}$ & \\
\hline AQ11 & Please check and confirm the inserted publisher location for the reference Olson et al. (1985). & \\
\hline
\end{tabular}

